\title{
“El paradigma de la pobreza evangélica y la dimensión social de la evangelización. Una lectura de la Evangelii Gaudium del Papa Francisco".
}

Rolando Echeverría ${ }^{1}$

Recibido en febrero de 2014 y aceptado en mayo de 2014

\begin{abstract}
Resumen
El autor aborda en esta conferencia, la dimensión social de la evangelización; la entiende, como el anuncio de la buena nueva de Jesucristo. Piensa que la dimensión social de la evangelización está muy vinculada con la actual situación económica y social, y que por ello es muy relevante para todos aquellos seres humanos que se comprometan con la transformación de esa realidad.
\end{abstract}

Palabras claves

Evangelización, dimensión social humana, situación económica y social, compromiso social.

\begin{abstract}
In this lecture, the author discusses the social dimension of evangelization, understood as the proclamation of the Good News of Jesus Christ. He believes that the social dimension of evangelization is closely linked to the current economic and social situation, and therefore it is highly relevant to all those committed to the transformation of that reality.
\end{abstract}

\section{Keywords:}

Evangelization, Human social dimension, economic and social situation, social commitment.

Quiero comenzar agradeciendo a las autoridades de la Universidad el haberme dirigido la invitación a presentar esta lección inaugural. Lo considero un honor y es para mí un gusto poder compartirles mi reflexión en este momento siempre significativo de la vida académica de una institución de educación superior como esta.

1. Dr. En filosofía, profesor del Instituto Filosófico Salesiano y de la Universidad Mesoamericana Guatemala. E-mail: rolech50@yahoo.com 
Agradezco también a todos los presentes que me brindan el honor de su presencia, de su tiempo y de su atención.

Cuando pregunté acerca del tema que deseaban que disertara, se me sugirió tomar como referencia el capítulo cuarto de la Exhortación Evangelii Gaudium del Papa Francisco, sobre la dimensión social de la evangelización. La sugerencia me pareció muy acertada por varios motivos: se trata, en primer lugar, de un tema de actualidad, un tema que no debe pasar desapercibido en una universidad que se guía por principios humanistas y cristianos; es un documento, además, que está dirigido a todos los cristianos que queremos y debemos ser conscientes de nuestra vocación y de nuestro compromiso; es importante también por provenir de una persona que se está revelando como un gran líder de la humanidad en la actualidad, un guía espiritual que suscita esperanza y optimismo en un mundo tan convulsionado como el de la presente época; y es ocasión propicia para tomar contacto con un documento valioso, que muchas veces corre el riesgo de quedarse en noticia pasajera, sobrepasado por la avalancha de continuos mensajes que nos llegan en esta era de la información.

Para la presente exposición he querido dejarme guiar por cuatro preguntas, que creo pueden ayudarnos a centrar el tema de esta conferencia. Las preguntas son las siguientes:

- ¿Qué tiene que ver la evangelización con la dimensión social humana?

- ¿Cuál es el análisis o diagnóstico que hace el Papa de la situación económica y social en la actualidad?

- ¿Cuál es la propuesta del evangelio en el ámbito de la dimensión social?

- ¿Qué actitudes y compromisos nos pide el Papa Francisco en lo referente a la dimensión social?

\section{1. ¿Qué tiene que ver la evangelización con la dimensión social humana?}

Conviene recordar que la Exhortación Apostólica Evangelii Gaudium (El gozo del Evangelio) es fruto de la XIII Asamblea General Ordinaria del Sínodo de los Obispos, que se celebró en Roma del 7 al 28 de octubre de 2012, bajo el tema La nueva evangelización para la transmisión de la fe cristiana. En ese entonces la Iglesia católica estaba todavía bajo el pontificado de Benedicto XVI. Su sucesor, el papa Francisco, recogió el valioso material de ese encuentro mundial de obispos para ofrecernos el documento en cuestión, dándole, evidentemente, su sello personal y una redacción muy a su estilo.

Quiere decir que el tema central de la presente Exhortación es la evangelización, entendida como el anuncio de la buena nueva de Jesucristo. El papa Francisco lo dice claramente desde el inicio: "En esta Exhortación quiero dirigirme a los fieles cristianos para invitarlos a una nueva etapa evangelizadora marcada por 
la alegría, e indicar caminos para la marcha de la Iglesia en los próximos años" (1). Fijémonos en el tono positivo, optimista y en el carácter programático con que nos ofrece el actual papa este documento.

No es entonces la Exhortación un texto de doctrina social en sí mismo, sino más bien de intención pastoral. Por eso considero que es pertinente hacerse la pregunta de este primer subtema, que podríamos formular también de esta manera: ¿incluye la evangelización, en sí misma, la dimensión socioeconómica y política? ¿o ha de considerarse ésta como un añadido, un anexo o apéndice deseable, pero no necesariamente inherente al mensaje evangélico?

Es sabido que la Iglesia -el Magisterio en particular- ha recibido críticas de diversos sectores cuando se pronuncia sobre temas que tienen que ver con la vida social, económica, política, particularmente cuando ha asumido una actitud crítica hacia decisiones, actividades o leyes que considera lesivas para el ser humano. Sin embargo, la misma Iglesia, en diversos documentos, ha defendido con fuerza el derecho y el deber de pronunciarse para iluminar las conciencias de los cristianos y de los hombres de buena voluntad, a la luz del evangelio y de la recta razón.

Es preciso poner de relieve que el destinatario de la evangelización es el ser humano; y que la finalidad de la evangelización es su salvación en sentido pleno. De fondo hay una visión antropológica que considera al ser humano como un todo integral de cuerpo y espíritu. Hay que reconocer que en los primeros siglos la teología cristiana sufrió el influjo del dualismo antropológico característico de la cultura griega, particularmente por la simpatía que manifestaron los primeros teólogos hacia la filosofía de Platón y el Neoplatonismo, lo que dejó su huella en los Padres de la Iglesia, en especial en san Agustín, quien marcó toda una época en Occidente. Son conocidas las expresiones de Platón acerca del cuerpo como prisión o tumba del alma; su ética basada en el cultivo del alma y la mortificación del cuerpo; su concepción de la muerte como liberación del alma de los lazos del cuerpo. Afortunadamente dicha concepción antropológica dualista fue en buena parte superada en siglos posteriores por otra de corte aristotélico, más equilibrada, asumida, entre otros, por santo Tomás de Aquino, donde prevalece la unidad corpóreo espiritual del ser humano, visión más en consonancia con la doctrina bíblica. Justamente dicha perspectiva va a representar un aporte decisivo en el desarrollo del concepto de persona.

La toma de conciencia de la Iglesia acerca de los problemas sociales, particularmente en los últimos dos siglos, junto con una renovada reflexión filosófica acerca del hombre y una teología más encarnada, ha llevado al Magisterio a una maduración doctrinal en este ámbito. Ya el papa Pablo VI, en un documento que precisamente también se refería a la evangelización, la encíclica Evangelii nuntiandi, declaraba que entre evangelización y promoción humana existen vínculos "de orden antropológico, porque el hombre que 
hay que evangelizar -decía- no es un ser abstracto, sino un ser sujeto a los problemas sociales y económicos." (EN, 29)

Y el mismo Pablo VI, en otra de sus encíclicas, citada por el papa Francisco en la Exhortación que comentamos, subrayaba que el desarrollo es "de todos los hombres y de todo el hombre", señalando así dos criterios complementarios: la universalidad y la integralidad del desarrollo, para que éste pueda llamarse verdaderamente humano y no se reduzca a lo puramente material.

El papa Francisco, haciéndose eco de esta renovada concepción teológica, sale al paso de las usuales objeciones, fruto de una superada visión dualista platónico-agustiniana, señalando que "ya no se puede decir que la religión debe recluirse en el ámbito privado y que está sólo para preparar almas para el cielo" (182). Y añade que la tarea evangelizadora implica y exige una promoción integral de cada ser humano.

Ya lo decía uno de los documentos más significativos del Concilio Vaticano II, la Constitución Gaudium et Spes, abriendo con palabras llenas de humanidad: "Los gozos y las esperanzas, las tristezas y las angustias de los hombres de nuestro tiempo, sobre todo de los pobres y de cuantos sufren, son a la vez gozos y esperanzas, tristezas y angustias de los discípulos de Cristo. Nada hay verdaderamente humano que no encuentre eco en su corazón" (GS 1).

En esta línea el papa Francisco subraya: "nadie puede exigirnos que releguemos la religión a la intimidad secreta de las personas, sin influencia alguna en la vida social y nacional...Una auténtica fe -que nunca es cómoda e individualistasiempre implica un profundo deseo de cambiar el mundo, de transmitir valores, de dejar algo mejor detrás de nuestro paso por la tierra" (183).

No podía faltar en el documento la referencia a una categoría central en el evangelio y que ha sido fruto de una larga y muy rica reflexión en la teología cristiana de los últimos tiempos: el Reino de Dios. El papa proclama que el proyecto de Jesús es "instaurar el Reino de su Padre". Hacer que Dios reine significa erradicar todo aquello que oprime o esclaviza al ser humano, todo lo que impide su pleno desarrollo, en todas sus dimensiones: humana y espiritual, individual y social, histórica y escatológica. Si anunciar el evangelio es instaurar el Reino de Dios, la dimensión social es inherente al anuncio de la buena nueva. Como dice el mismo papa Francisco: "En la medida en que Él logre reinar entre nosotros, la vida social será ámbito de fraternidad, de justicia, de paz, de dignidad para todos. Entonces, tanto el anuncio como la experiencia cristiana tienden a provocar consecuencias sociales" (180).

Pero hay además otro motivo, de naturaleza ética y teologal, que fundamenta la imprescindible dimensión social de la evangelización: el servicio de la caridad. 
Sabemos bien que la caridad es el núcleo central de la moral evangélica. Es, por un lado, una virtud teologal y, en cuanto tal, don de Dios, es acoger el amor de Dios mismo; pero también se puede considerar virtud moral, fruto del compromiso del cristiano consciente de su vocación. El papa lo señala, citando frases evangélicas muy significativas al respecto: «Sed compasivos como vuestro Padre celestial es compasivo» (LC 6,36); «Lo que hicisteis a uno de estos hermanos míos más pequeños, lo hicisteis a mí» (Mt 25,40). Y subraya que: "Así como la Iglesia es misionera por naturaleza, así también brota ineludiblemente de esa naturaleza la caridad efectiva con el prójimo, la compasión que comprende, asiste y promueve" (179).

Con estos argumentos, considero que podemos dar por suficientemente respondida la primera pregunta.

\section{2. ¿Cuál es el análisis o diagnóstico que hace el Papa de la situación económica y social en la actualidad?}

Como en otros documentos del Magisterio, el papa Francisco aclara como premisa que se propone dirigir "una mirada pastoral", a "algunos aspectos de la realidad que pueden detener o debilitar los dinamismos de renovación misionera de la Iglesia" (51).

Ciertamente, como dice esa magnífica obra que es el Compendio de la Doctrina Social de la Iglesia, el Magisterio se vale de los aportes de la filosofía y de las ciencias humanas, para estar en sintonía con cada época y para responder a las distintas situaciones que la humanidad va viviendo, en su contexto histórico, social, político, económico. Sin embargo, la contribución de la Iglesia no es en el ámbito científico-técnico, que no le corresponde, sino en plano religioso y moral.

Es en esta perspectiva de iluminación pastoral donde se coloca la Exhortación. Podría argumentarse que el análisis de la situación contemporánea que hace el papa Francisco es bastante limitado en el presente documento. Quizás por eso el pontífice se adelanta a tal objeción, advirtiendo que el suyo no pretende ser un análisis exhaustivo, sino busca más bien poner de relieve algunos aspectos de la realidad actual, aquellos que tienen mayor incidencia en el dinamismo de la evangelización en el momento presente que vive la Iglesia.

La Exhortación hace referencia a ciertos rasgos de la época en el ámbito cultural; alude también a algunos temas de orden social, como el de la violencia, la familia, la tendencia al individualismo; pero sobre todo se centra en el tema económico, deteniéndose en el problema de la pobreza, la inequidad y la exclusión, cuestiones a las que el actual papa es muy sensible. 
No deja de señalar el documento aspectos positivos en el campo de lo económico y social: "los avances que contribuyen al bienestar de la gente, como, por ejemplo, en el ámbito de la salud, de la educación y de la comunicación". Y alaba también otros logros que inciden en el progreso de la sociedad, reconociendo "enormes saltos cualitativos, cuantitativos, acelerados y acumulativos que se dan en el desarrollo científico, en las innovaciones tecnológicas y en sus veloces aplicaciones en distintos campos de la naturaleza y de la vida... estamos en la era del conocimiento y la información" (52).

Sin embargo, gran parte de la humanidad no llega a disfrutar de tales logros, por la situación de pobreza, ya que "la mayoría de los hombres y mujeres de nuestro tiempo vive precariamente el día a día, con consecuencias funestas"... (52)

Es justamente en el análisis de la situación económica donde el papa se muestra más crítico. Hay dos términos que resaltan al respecto: «inequidad» y «exclusión». Ciertamente su condición de latinoamericano hace que el papa actual tenga una visión cercana, podríamos decir experiencial, de la inequidad. Vivimos en el continente donde la desigualdad económica es más pronunciada, pues la riqueza de recursos y de producción se contrapone a la flagrante desigualdad en la distribución, tal como señala el documento de Aparecida, en cuya elaboración el entonces cardenal Bergoglio fue directo protagonista. En una de sus frases, la Exhortación expresa con fuerza la inequidad producida por el afán de lucro desmedido: “Mientras las ganancias de unos pocos crecen exponencialmente, las de la mayoría se quedan cada vez más lejos del bienestar de esa minoría feliz" (56).

Hablando de la exclusión, la deficiente organización de la economía en el mundo contemporáneo hace que hoy ya no se pueda hablar solamente de "explotación de los trabajadores" o de "obreros oprimidos", según lenguaje usual de un reciente pasado, sino que se ha ido aún más lejos. Para grandes masas no se trata sólo de estar en el punto más bajo de la pirámide económica y social. El papa ve un problema más grande, aludiendo a una cultura del "descarte", que es incluso promovida por la forma de organización social y económica. Es decir, que ingentes cantidades de personas son desechadas, ya no se les considera incluidas en la sociedad, sino que van quedando relegadas, en la periferia, como elementos "sobrantes". Se ven imposibilitadas de sumarse a la actividad productiva $\mathrm{y}$, consiguientemente, terminan siendo excluidas del entramado social, condenadas a un régimen de mera sobrevivencia, "sin trabajo, sin horizontes, sin salida" (53).

Al respecto de esta situación, el papa se atreve a señalar algunas causas que llevan a las situaciones de inequidad y exclusión. Una de ellas reside en una economía organizada en torno a la "ley del más fuerte, donde el poderoso se come al más débil”. Particularmente critica el papa lo que él llama "las teorías 
del «derrame», que suponen que todo crecimiento económico, favorecido por la libertad de mercado, logra provocar por sí mismo mayor equidad e inclusión social en el mundo" (54). No ve el papa que esto se cumpla en la realidad concreta. Sin nombrar una doctrina en particular, se pueden reconocer tras estas palabras los principios de una economía de corte neoliberal.

Bien sabemos que la doctrina social de la Iglesia avala la economía del libre mercado. Juan Pablo II, en la Centesimus annus, afirma que hay buenas razones para considerar que "el libre mercado sea el instrumento más eficaz para colocar los recursos y responder eficazmente a las necesidades" (CA, 34). Pero asimismo es clara la doctrina de la Iglesia al afirmar que no se puede confiar simplemente a los mecanismos de la lógica del mercado el conseguimiento del bien común. El mercado es un instrumento y no debe constituirse en el fin de la actividad humana, que es el desarrollo integral de las personas. Justamente en relación con este punto señala el papa otra de las causas de la inequidad y la exclusión, que gira en torno a una equivocada manera de concebir al hombre. En sus palabras: "La crisis financiera que atravesamos nos hace olvidar que en su origen hay una profunda crisis antropológica: ¡la negación de la primacía del ser humano!" (55). Como sabemos, uno de los principios fundamentales de la doctrina social de la Iglesia y de la ética cristiana es la primacía de la persona, que el papa subraya en repetidas ocasiones. La economía debe estar al servicio de las personas, y no al revés.

Añadiría que tal concepción individualista y egoísta de la economía olvida dos principios fundamentales que propone la doctrina social de la Iglesia: el de subsidiariedad y el de solidaridad. Tales principios son complementarios y, por consiguiente, deben combinarse armoniosamente para que la vida económica y social cumpla sus fines en función del desarrollo de las personas. El principio de subsidiariedad defiende que la sociedad debe garantizar la libertad e iniciativa de los individuos y grupos menores para que éstos atiendan por sí mismos, en lo posible, sus propias necesidades. Expresado en sentido restrictivo, el principio dice que el Estado o los grupos mayores no deben intervenir allí donde los individuos o grupos menores pueden desarrollarse por sí mismos y resolver sus propios problemas. En sentido positivo, Estado y grupos mayores están llamados a intervenir en los casos o situaciones en que los individuos o grupos menores no se basten a sí mismos para satisfacer sus necesidades y encuentren así graves obstáculos para su propio desarrollo.

Este principio de subsidiariedad busca tomar distancia de toda actitud paternalista, que frenaría la iniciativa y creatividad de las personas, como es el caso de la economía colectivista o centralizada por el Estado. Pero marca su distancia también de una mentalidad eminentemente individualista, propia del liberalismo radical, que se opone a la intervención y apoyo de parte del Estado o de los grupos mayores con respecto a los individuos o grupos menores. Dicho principio tiende a delinear una actitud prudente, que favorezca la iniciativa 
privada y la autonomía, pero a la vez propicie la ayuda y promoción de los más desfavorecidos, según sus necesidades.

El principio de solidaridad, por su parte, deriva de la convicción de la igual dignidad de los seres humanos y de sus derechos, así como de la natural sociabilidad del hombre. Subraya además la corresponsabilidad en el desarrollo y el vínculo de interdependencia entre los hombres y los pueblos. Dicho principio tiene implicaciones morales, pues fomenta el compromiso de ayuda mutua y tiende a neutralizar el individualismo egocéntrico, buscando que todos los ciudadanos se sientan corresponsables del desarrollo de los distintos miembros de la sociedad. Expresión de este principio es la idea del destino universal de los bienes y de la tierra como planeta del que todos sus habitantes tenemos derecho a gozar. Para decirlo en palabras del papa, "la tierra es nuestra casa común y todos somos hermanos" (183).

Otra de las causas de la inequidad y la exclusión señaladas por el pontífice es la falta de ética. Señala el papa que "la ética suele ser mirada con cierto desprecio burlón. Se considera contraproducente, demasiado humana, porque relativiza el dinero y el poder" (57). A este respecto conviene recordar que eminentes filósofos antiguos, como Platón y Aristóteles, consideraban la política y la economía como ámbitos que debían estar sometidos a las normas de la ética, en función del bien de los ciudadanos. Fue la época moderna, construida sobre el individualismo del "yo pienso" de René Descartes, la que comenzó a proponer una desvinculación de dichas actividades humanas con la ética, en aras de una plena autonomía de los mecanismos productivos y en función de una mayor producción de riqueza. La doctrina social de la Iglesia, en cambio, de la cual el papa Francisco se hace portavoz, defiende la intrínseca vinculación entre moral y economía. La necesaria distinción entre los dos ámbitos no implica separación, sino reciprocidad, pues ambas tienen al ser humano como centro, como bien señala el documento Gaudium et Spes: "el hombre es el autor, el centro y el fin de toda la vida económico-social" (GS 63). Por eso, si bien la economía tiene sus propias leyes y mecanismos, éstos no pueden comprometer el bien integral de las personas. En este mismo ámbito de la falta de ética denuncia también el papa, como males de la sociedad contemporánea, la corrupción ramificada y la evasión fiscal.

La “idolatría del dinero" es otra de las causas de la grave situación económica de pobreza y exclusión. Utilizando la imagen bíblica de la adoración del becerro de oro, el papa alude al "fetichismo del dinero" en que se ha caído, convirtiendo en fin su función de medio. Por eso el Papa afirma rotundamente: “¡El dinero debe servir y no gobernar!" (58).

Otro signo de la deficiente organización económica de la sociedad contemporánea es el consumismo. El ser humano queda reducido a una sola dimensión: el consumo, lo que es muestra, una vez más, de una deficiente concepción antropológica. 
Y hay un punto que toca muy de cerca la situación de nuestros países centroamericanos: la inseguridad y a violencia. A veces se pretenden combatir por medio de la fuerza y la represión. El papa pone el dedo en la llaga, apuntando a las raíces de tal situación: "Hoy en muchas partes se reclama mayor seguridad. Pero hasta que no se reviertan la exclusión y la inequidad dentro de una sociedad y entre los distintos pueblos será imposible erradicar la violencia" (59). Es una situación que no se resuelve simplemente con el recurso a la represión, mientras no se ataquen las verdaderas causas.

\section{3. ¿Cuál es la propuesta del evangelio en el ámbito de la dimensión social?}

El capítulo cuarto de la Exhortación corresponde a la dimensión social de la evangelización. Dedicar todo un capítulo a este tema es signo de la importancia que le quiere dar el pontífice. Justamente este apartado abre con una frase muy significativa: "Evangelizar es hacer presente en el mundo el Reino de Dios" (176). Sabemos que el Reino es una categoría que implica dos dimensiones: terrenal y espiritual. Para el papa, sin la dimensión social debidamente explicitada, la evangelización no sería completa y se desvirtuaría con ello la misión de la Iglesia.

El papa va a abordar aquí cuatro puntos. El primero referente al anuncio del evangelio, al kerygma, que es como la motivación de fe que está detrás de los otros tres puntos: el tema de la inclusión social de los pobres, el tema de la paz y el tema del diálogo como medio para promover la paz. Hace justamente un año el papa escogía el nombre de Francisco para identificar su pontificado. Bajo ese nombre se encierran dos grandes preocupaciones del papa, que quieren ser a la vez dos grandes líneas programáticas suyas y que él quiere, a su vez, imprimir a la Iglesia que Dios le ha encomendado dirigir: los pobres y la paz. No es extraño, pues, que ambos temas estén muy presentes en este capítulo del documento y que en ellos enfoque su propuesta.

Algo que resalta como motivación y fundamentación de la dimensión social de la evangelización es el kerygma: el papa subraya que en la proclamación de la buena nueva "está la vida comunitaria y el compromiso con los otros", con una ineludible "repercusión moral cuyo centro es la caridad” (177).

La fe en el Dios trinitario, corazón del evangelio, conduce a una particular concepción del hombre, que es el destinatario de la buena nueva y, por consiguiente, del amor salvífico de Dios. Como bien señala el papa, confesar a un Padre que ama infinitamente a cada ser humano implica descubrir que «con ello le confiere una dignidad infinita». Confesar que el Hijo de Dios asumió nuestra carne humana significa que cada persona humana ha sido elevada al corazón mismo de Dios. Confesar que el Espíritu Santo actúa en todos implica reconocer que Él procura penetrar toda situación humana y todos los vínculos sociales. Es la misma fe en el misterio trinitario la que nos lleva a reconocer 
que "fuimos hechos a imagen de esa comunión divina, por lo cual no podemos realizarnos ni salvarnos solos" (178).

Estas palabras del papa recuerdan a uno de los grandes teólogos del siglo XII, Ricardo de San Víctor. El hecho de que el ser humano ha sido creado a imagen y semejanza de Dios se ha interpretado generalmente en relación con la inteligencia y la consiguiente capacidad de verdad y de libre albedrío con que cuenta el hombre. Sin embargo, cuando el mencionado teólogo medieval comenta lo de "imagen y semejanza", lo relaciona con el amor de Dios, con el Dios trinitario, que es comunión total de personas. Con lo cual subraya que el ser imagen y semejanza de Dios implica en el hombre acoger el amor de Dios e imitar la comunión trinitaria de las personas entre los seres humanos. Así, ser imagen y semejanza de Dios es un compromiso que lleva a la caridad con el prójimo. Sin mencionarlo, el papa se sitúa en esta misma línea, al señalar que "dejarse amar por Dios y amarlo con el amor que él mismo nos comunica" provoca una primera y fundamental reacción en el creyente: “desear, buscar y cuidar el bien de los demás" (178). Porque procedemos del amor del Dios uno y trino, que es comunión, estamos llamados a promover el amor de comunión entre las personas.

No deja de señalar el papa la inseparable conexión entre la recepción del evangelio y un efectivo amor fraterno, por lo que en repetidos textos neotestamentarios que él cita, señala que la moral cristiana une, como si fueran uno solo, los dos mandamientos del amor a Dios y el amor al prójimo. Dicha convicción está expresada en la proclamación del Reino, como ya se ha hecho notar, que tiene claras repercusiones sociales, bajo el distintivo de la caridad y la compasión.

\section{Inclusión de los pobres}

Uno de los ámbitos en que se ha de proyectar la dimensión social del evangelio es la opción por los pobres. Así como en el análisis de la situación el papa resaltaba la exclusión, como uno de los índices deplorables de la sociedad contemporánea, así ahora nos habla de "la inclusión social de los pobres".

Se sirve el pontífice de varios textos de la Escritura para subrayar el compromiso de la evangelización en favor de la liberación y promoción de los pobres para que puedan integrarse plenamente a la sociedad. La Iglesia no puede menos que seguir el ejemplo de un Dios que escucha el clamor de los pobres y baja para liberarlos de la opresión que sufren en Egipto, así como el modelo de Cristo, que se hizo pobre y se manifestó siempre "cercano a los pobres y excluidos".

Es por eso que la Iglesia propone la solidaridad, como aquella "mentalidad que piense en términos de comunidad, de prioridad de la vida de todos sobre la apropiación de los bienes por parte de algunos" (188). Solidaridad que lleva a reconocer, en palabras que recuerdan a Juan Pablo II, "la función social de la 
propiedad y el destino universal de los bienes como realidades anteriores a la propiedad privada" (189).

Preocuparse por la inclusión de los pobres es algo que brota de la fe, del compromiso ético, de convicciones profundas en cuanto a la caridad. Pero no se puede quedar en meros proyectos o en buenas intenciones, sino que debe provocar, como dice el papa, cambios estructurales, entre los que menciona: "decisiones, programas, mecanismos y procesos específicamente orientados a una mejor distribución del ingreso, a una creación de fuentes de trabajo, a una promoción integral de los pobres que supere el mero asistencialismo" (204). No se debe buscar solamente asegurar a todos la comida, sino la prosperidad en sentido plenario, que implica educación, cuidado de la salud, trabajo; un trabajo "libre, creativo, participativo y solidario", donde el hombre pueda expresar y acrecentar su dignidad (192). Un trabajo que asegure el salario justo, que permita el acceso a los bienes destinados al uso común.

Por contraposición, expresado en sentido negativo, el crecimiento en equidad y en la línea de la inclusión exige, según el papa: "renunciar a la autonomía absoluta de los mercados y de la especulación financiera" (202); no basar la economía "en las fuerzas ciegas y en la mano invisible del mercado" (204); no pretender aumentar la rentabilidad "reduciendo el mercado laboral y creando así nuevos excluidos" (204).

En este punto el papa hace un llamado a los políticos, para que entren en un diálogo que lleve a sanar las raíces profundas de los males del mundo actual. Recuerda que la política es una altísima vocación, "una de las formas más preciosas de la caridad". Ésta no debe reducirse sólo a las micro-relaciones: amistades, familia, pequeño grupo, sino a las macro-relaciones: las sociales, económicas, políticas (205). Y pronuncia una exclamación que brota de sus entrañas llenas de compasión: “¡Ruego al Señor que nos regale más políticos a quienes les duela de verdad la sociedad, el pueblo, la vida de los pobres!" (205).

Un apartado particular dedica el documento bajo el título "cuidar la fragilidad", en donde el papa alude a "nuevas formas de pobreza", mencionando a los sin techo, los tóxicodependientes, los refugiados, los pueblos indígenas, los ancianos, los migrantes. No se queda atrás el tema de la trata de personas, de las mujeres que sufren exclusión, maltrato y violencia, los niños por nacer, e incluso los bienes de la creación, de los cuales el ser humano debe ser custodio y no destructor.

\section{El tema de la paz}

Después de esta propuesta en favor de la inclusión de los pobres, pasa el papa al otro tema muy querido para él, el de la paz. 
Denuncia, ante todo, una falsa concepción de la paz: la paz no consiste en evitar las tensiones, como fruto de la imposición de un sector sobre los otros, particularmente cuando se logra silenciar a los pobres para beneficio de un grupo de privilegiados. Tampoco es la paz mera ausencia de guerra.

La auténtica paz ha de ser fruto del desarrollo integral de todos. El tema de la paz está así en relación con lo que ha expuesto anteriormente sobre la inclusión de los pobres. Para lograr dicha paz, que es un proceso lento y arduo, el papa propone cuatro principios relacionados con tensiones bipolares y que brotan de la doctrina social de la Iglesia.

\section{El tiempo es superior al espacio}

El papa se refiere al tiempo como un continuo que se abre ilimitado, en contraposición al espacio, horizonte limitado. Lo interpreta como la necesidad de trabajar en la perspectiva del largo plazo, sin dejarse llevar por la premura de resultados inmediatos y buscar seguridades o compromisos que resuelven situaciones pasajeras, sin apuntar a verdaderos procesos. Lamentablemente - parece decir el papa- lo que prevalece en el mundo actual es la búsqueda de logros inmediatos, que producen un "rédito político fácil, rápido y efímero", pero que no apunta a la plenitud humana. Sugiere, pues, el papa buscar soluciones de largo plazo, sin caer en la tentación del inmediatismo oportunista.

\section{La unidad prevalece sobre el conflicto}

El papa hace ver que el conflicto, las tensiones, los opuestos, no son de por sí realidades destructivas en la sociedad. El conflicto es algo que acompaña la convivencia humana, por la diversidad y pluriformidad de personas, grupos, culturas, sociedades. Las tensiones entre personas y grupos pueden ser una riqueza si se saben afrontar y asumir. Lo importante es abordarlos con la actitud correcta, poniendo la unidad por encima del conflicto, buscando alcanzar la unidad en la diversidad. Al respecto, pone el ejemplo de Cristo, que nos alcanzó la paz mediante la sangre de su cruz; y del Espíritu Santo, dinamismo que armoniza las diversidades. Para la comunidad eclesial, eso significa buscar el equilibrio de la comunión en el respeto al pluralismo, evitando el peligro de una estéril uniformidad.

\section{La realidad es más importante que la idea}

Se refiere aquí el papa a la bipolaridad tensional entre teoría y praxis. Entre la idea y la realidad es necesario un diálogo constante. Evitar, por un lado, que las elaboraciones conceptuales se separen de la realidad, donde más bien deben encontrar su banco de prueba. Ni quedarse en el mundo de los ideales, ni impedir que la realidad sea iluminada por el razonamiento. Traducido al campo eclesial, eso significa poner en práctica la Palabra, que el anuncio no se quede en palabras, sino que se traduzca en obras de justicia y caridad. 


\section{El todo es superior a la parte}

Una visión de la realidad en perspectiva global no debe hacer perder de vista la realidad local, evitando dos extremos: el universalismo abstracto y el hermetismo localista. Hay que ampliar la mirada para reconocer un bien mayor que nos beneficia a todos, pero sin evadir el ámbito local ni olvidar las raíces de la propia historia y del propio lugar.

Concluye el papa la propuesta de la Iglesia aludiendo al diálogo como medio para alcanzar la paz. Aborda este tema refiriéndolo a tres ámbitos: el diálogo de la Iglesia con los Estados; el diálogo con la sociedad, que incluye una actitud de apertura al mundo de la cultura y al mundo de las ciencias; el diálogo con los creyentes que no forman parte de la Iglesia católica e incluso con los no creyentes. No hay duda que el diálogo y la búsqueda de la unidad son actitudes que están en el corazón del papa actual.

\section{4. ¿Qué actitudes se nos pide a los cristianos en lo referente a la dimensión social?}

El tema de la presente conferencia hacía referencia al paradigma de la pobreza evangélica y seguramente los más perspicaces habrán notado que hasta ahora no he hecho alusión al mismo. Pues bien, me propongo tratarlo en relación con esta última pregunta que cierra mi discurso, inspirándome siempre en el documento del papa. No es que él trate explícitamente este tema, pero está sugerido de alguna manera y la lectura de su texto a mí me lo sugiere, sobre todo cuando el papa trata el argumento de la inclusión de los pobres.

Llama la atención que la primera de las bienaventuranzas de Jesús se refiere a los pobres, tanto en la versión de Mateo: «Bienaventurados los pobres de espíritu, porque de ellos es el Reino de los Cielos» (Mt 5,3), como en la versión de Lucas «Bienaventurados los pobres, porque de ustedes es el Reino de Dios» (LC 6, 20).

Los especialistas en la Sagrada Escritura señalan que el llamado discurso de las bienaventuranzas es una declaración solemne que expresa la novedad radical del mensaje de Jesús. En ese sentido, las bienaventuranzas son una proclama de los valores del Reino de Dios, que constituye el núcleo central de la predicación y de la acción de Jesucristo. Fijémonos entonces que Jesús asocia la pobreza con el Reino, con el núcleo de la proclamación de la buena noticia que él nos trae de parte de Dios, su Padre.

En este sentido, uno podría preguntarse: ¿entonces todos los cristianos debemos ser pobres? ¿significaría eso, en consecuencia, que es malo o contrario al evangelio ser rico o buscar enriquecerse? 
La respuesta a esas preguntas tiene muchos matices, puesto que ni la pobreza ni la riqueza son términos unívocos en la Escritura, sino ambivalentes. Hay una pobreza buena y deseable, la que recomienda Jesús; y hay otra pobreza que es mala, denigrante, que más bien perjudica al ser humano, porque impide su pleno desarrollo. Igualmente hay una riqueza que es deseable y una forma de riqueza o de enriquecimiento que ha de evitarse.

El papa, en su Exhortación, nos recuerda cómo Jesús, cuyos discípulos somos, asumió él mismo la pobreza: "El Salvador nació en un pesebre, entre animales, como lo hacían los hijos de los más pobres; fue presentado en el Templo junto con dos pichones, la ofrenda de quienes no podían permitirse pagar un cordero (cf. Lc 2,24; Lv 5,7); creció en un hogar de sencillos trabajadores y trabajó con sus manos para ganarse el pan" (197). Siguiendo al papa, podríamos acumular otras varias citas referentes a la pobreza de Jesús, como cuando, a uno que quiere seguirle, el Maestro le dice: «Las zorras tienen guaridas y las aves del cielo nidos; pero el Hijo del hombre no tiene dónde reclinar la cabeza» (Mt $8,20)$. Es evidente que Jesús hizo una opción personal por vivir pobremente.

Es clara también en Jesús la exhortación a la pobreza en sus discípulos: «No anden preocupados por su vida, qué comerán, ni por su cuerpo, con qué se vestirán. ¿No vale más la vida que el alimento, y el cuerpo más que el vestido?... Busquen primero el Reino de Dios y su justicia, y todo lo demás se les dará por añadidura». (Mt 6,25.33)

Jesús los exhorta además a vivir una actitud de desprendimiento y de plena confianza en Dios: «No acumulen tesoros en la tierra, donde hay polilla y herrumbre que corroen, y ladrones que socavan y roban. Acumulen más bien tesoros en el cielo, donde no hay polilla ni herrumbre que corroan, ni ladrones que socaven y roben. Porque donde esté tu tesoro, allí estará también tu corazón» (Mt 6,19-21).

La verdadera riqueza, la riqueza deseable, para Jesús, la que da la felicidad auténtica, no está en los bienes materiales, sino en acoger el amor de Dios, el Reino, como el verdadero tesoro, ante el cual todo lo demás queda relativizado, como está ejemplificado en las parábolas del tesoro y la perla. (Mt 13,44-46)

Evidentemente, generar riqueza en la sociedad no es malo. Querer tener éxito en los negocios, en la empresa, en actividades financieras, si se hace con honestidad, son actividades que redundan en beneficio de la población y que contribuyen significativamente al bienestar de muchas personas. La doctrina social de la Iglesia reconoce la bondad de la actividad económica en sí misma. Pero ésta debe estar enmarcada en los principios de la ética y, para el cristiano, en los principios de la caridad evangélica. 
Por el contrario, hay una riqueza que se debe rechazar, que parte de una actitud desviada del corazón, cuando el hombre hace de los bienes de este mundo el centro de su vida y pone en ellos su esperanza, en lugar de poner a Dios en el primer lugar y dar acogida a su prójimo. Por eso dice tajantemente Jesús: «Nadie puede servir a dos señores; porque aborrecerá a uno y amará al otro; o bien se entregará a uno y despreciará al otro. No pueden servir a Dios y al Dinero» (Mt 6,24). En este punto, como dicen los entendidos, Jesús utiliza la palabra aramea "Mammón" -"no pueden servir a Dios y a Mammón"-, personificando las riquezas, como si fueran un dios, un ídolo en el cual el hombre pone su confianza. Justamente es lo que el papa en la Exhortación denuncia como la idolatría del dinero. Como en el caso del becerro de oro, en el pasaje del Éxodo ya aludido, muchos hacen del dinero su propio dios. Esa es la riqueza no deseable, aquella en que ya no hay lugar para Dios ni, en consecuencia, para el prójimo. La acumulación, el lucro, el disfrute, el consumo desmesurado, se convierten en la meta que focaliza los esfuerzos y energías de personas y grupos, exacerbando el egoísmo. Tales personas, comúnmente ensalzadas por su éxito material, reciben el reproche de Jesús: «jay de ustedes, los ricos!, porque ya han recibido su consuelo» (Lc 6,26). La parábola de Epulón y el pobre Lázaro es un claro ejemplo de tal actitud que Jesús reprocha, por estar en neta contradicción con el evangelio, con el proyecto del Reino. Lo peor, como denuncia el papa, es que tales actitudes se han convertido en cultura y han llegado a formar parte constitutiva de la estructura de nuestra sociedad globalizada, provocando el empobrecimiento y la exclusión de grandes masas. Esta forma de idolatría tiene, como la otra cara de la moneda, lo que el papa señala con el nombre de la "globalización de la indiferencia”, esa indiferencia que impedía al rico ver la necesidad del pobre Lázaro o la indiferencia del sacerdote y el levita ante el hombre que había caído en manos de los ladrones. Los que viven en situaciones privilegiadas, fácilmente se aferran a sus intereses, desinteresándose de las necesidades de los otros.

Pero Jesús no sólo asumió personalmente la pobreza como estilo de vida y la recomendó a sus discípulos, sino que hizo una opción por los pobres, a quienes declaró "bienaventurados”. Como dice el Papa en su texto: "Cuando comenzó a anunciar el Reino, lo seguían multitudes de desposeídos, y así manifestó lo que Él mismo dijo: «El Espíritu del Señor está sobre mí, porque me ha ungido. Me ha enviado para anunciar el Evangelio a los pobres» $($ LC 4,18). A los que estaban cargados de dolor, agobiados de pobreza, los tenía en el centro de su corazón: «iFelices vosotros, los pobres, porque el Reino de Dios os pertenece! » (Lc 6,20); con ellos se identificó: "Tuve hambre y me disteis de comer», y enseñó que la misericordia hacia ellos es la llave del cielo (cf. Mt 25,35s)". (197)

Los pobres son dichosos porque Dios se ocupa de ellos, porque el Padre Dios es compasivo y misericordioso y escucha el clamor de los débiles, como lo manifiestan repetidamente los profetas. El amor compasivo y la predilección 
por el pobre la expresa Dios en plenitud por medio de su Hijo, el cual, "siendo rico se hizo pobre por ustedes, para enriquecerlos con su pobreza” (2 Cor 8,9). La bienaventuranza para los pobres se cumple en la medida en que sea acogido el proyecto de Dios, en la medida en que el Reino de Dios sea implantado y se haga parte de nuestra cultura, de una nueva civilización, la civilización del amor, de la cual hablaba Pablo VI. Pero ello exige que sea clara de parte nuestra la opción preferencial por los pobres.

Esta verdad la expresa el papa con palabras que no dejan lugar a dudas: "Si la Iglesia entera asume este dinamismo misionero, debe llegar a todos, sin excepciones. Pero ¿a quiénes debería privilegiar? Cuando uno lee el Evangelio, se encuentra con una orientación contundente: no tanto a los amigos y vecinos ricos sino sobre todo a los pobres y enfermos, a esos que suelen ser despreciados y olvidados, a aquellos que «no tienen con qué recompensarte» (Lc 14,14). No deben quedar dudas ni caben explicaciones que debiliten este mensaje tan claro. Hoy y siempre, «los pobres son los destinatarios privilegiados del Evangelio", y la evangelización dirigida gratuitamente a ellos es signo del Reino que Jesús vino a traer. Hay que decir que existe un vínculo inseparable entre nuestra fe y los pobres." (48)

Acoger el paradigma de la pobreza evangélica significa poner los valores del Reino en el centro de la vida personal y social. En una sociedad que privilegia el tener sobre el ser, en una sociedad donde se provoca inequidad y exclusión, el paradigma de la pobreza evangélica nos invita, como lo hace el Papa, a construir una sociedad nueva, fundada en la caridad, la solidaridad, la centralidad y dignidad de la persona, donde se privilegie a los más pobres y necesitados. No se trata simplemente de acciones asistencialistas, de quedarse en limosnas, pues eso no genera desarrollo sino dependencia. Hay que poner en acto, como decía el beato Juan Pablo II, la "creatividad de la caridad".

"Dichosos los pobres", es decir, los que son capaces de salir de sí mismos y de ver en los demás el rostro de Jesús. Dichosos porque, como dice el papa citando el documento de Aparecida, «La vida se acrecienta dándola y se debilita en el aislamiento y la comodidad». (9)

Agradezco profundamente su gentil atención y me consideraría sumamente satisfecho si esta reflexión que he compartido suscitara en ustedes el deseo de leer directamente -para los que aún no lo han hecho- la Exhortación del papa Francisco y, en todo caso, profundizarla ulteriormente para aprovechar toda su riqueza. Esa sería para mí la mejor recompensa.

Muchas gracias.

Dr. Rolando Echeverría San Salvador, 14 de Marzo de 2014 